\title{
Art and Parkinson's disease: a dramatic change in an artist's style as an initial symptom
}

\author{
Hideki Shimura $\cdot$ Ryota Tanaka $\cdot$ Takao Urabe $\cdot$ \\ Shigeki Tanaka $\cdot$ Nobutaka Hattori
}

Received: 24 May 2011/Revised: 21 September 2011/Accepted: 29 September 2011/Published online: 19 October 2011

(C) The Author(s) 2011. This article is published with open access at Springerlink.com

\begin{abstract}
In Parkinson's disease (PD), nonmotor symptoms manifest before motor symptoms. In this report, we present a remarkable case of a semiprofessional painter with PD whose painting style dramatically changed from abstract painting to realism before he developed motor, psychiatric, and autonomic nerve disorders. This case suggests that certain types of visual creativity may be impaired in the very early, presymptomatic stages of PD.
\end{abstract}

Keywords Parkinson's disease - Nonmotor symptoms · Abstract painting - Artistic expression .

Visuospatial system $\cdot$ Neurodegenerative disease

\section{Introduction}

Paintings represent the mindset, mood, skills, and preoccupations of a painter. Production of a novel, motivated, or useful material defines creativity, which is one of the higher, specific, human brain functions. Although creativity can be expressed in virtually any domain, art, in particular, illustrates how creativity may be modulated by normal or pathological brain functions. The effects of

H. Shimura $(\bowtie) \cdot$ R. Tanaka $\cdot$ T. Urabe $\cdot$ S. Tanaka

Department of Neurology, Juntendo University Urayasu

Hospital, 2-1-1 Tomioka, Urayasu, Chiba 113-8421, Japan

e-mail: hshimura@juntendo-urayasu.jp

\section{H. Shimura}

Institute for Environment and Gender Specific Medicine,

Urayasu, Japan

N. Hattori

Department of Neurology, Juntendo University School

of Medicine, Urayasu, Japan neurodegenerative diseases on artistic expression may vary depending on the extent of cognitive, behavioral, and motor dysfunction. Neurodegenerative disorder patients typically become artistically unskilled during disease progression.

In contrast, some patients may achieve new artistic expressions. In patients with frontotemporal dementia, new or improved creativity emerges in the context of degeneration of language areas [1-3]. In Alzheimer disease [4] with corticobasal degeneration [5], increasing abstraction with no deliberate stylistic effort has been associated with global cognitive impairment and visuospatial deficits. The majority of Parkinson's disease (PD) patients cannot sketch due to diminished motor skills. Changes in the artistic expression of PD patients during the course of the illness have been previously reported $[1,6]$. However, to our knowledge, there are no reports of neurodegenerative disease patients exhibiting drastic changes in their artistic skills before the onset of other symptoms.

Here, we present our observations of a semiprofessional painter with PD whose style changed dramatically from abstract to realism before the appearance of classic parkinsonian symptoms such as movement, psychiatric, and autonomic nerve disorders. Thus, this case represents alterations in the visual creativity occurring in the early presymptomatic stages of PD.

\section{Case report}

Our patient was a 68-year-old, right-handed, semiprofessional painter with a 7-year history of PD. In 2005, tremor and rigidity of the left arm appeared as his initial motor symptoms without psychiatric, autonomic, and sleep disorders. He started taking levodopa $(300 \mathrm{mg} /$ day $)$. His 
Fig. 1 a-f Abstract paintings from 1994-2004; date of completion. $\mathbf{g}$ and $\mathbf{h}$ Semiabstract paintings from 2004-2005. i Radish; j horse mackerel; k sweet potato; l lily; $\mathbf{m}$ arrowhead; and $\mathbf{n}$ pacific saury are realist paintings from 2005-2009

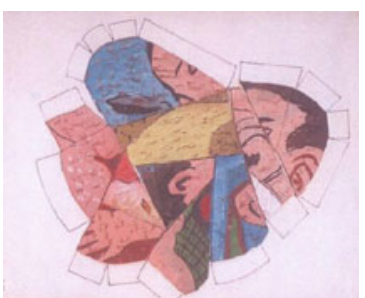

a 1993

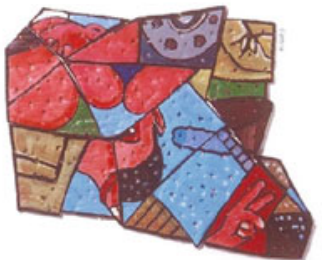

d 2000

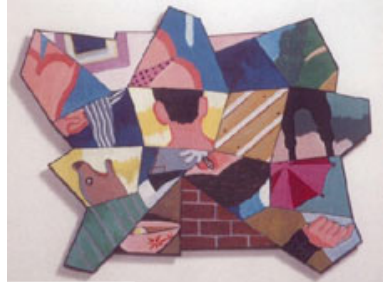

b 1995

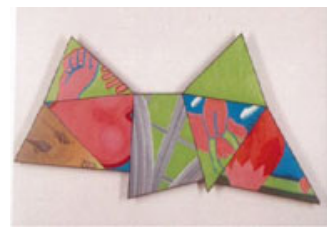

e 2002

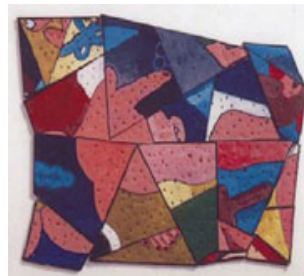

C 1997

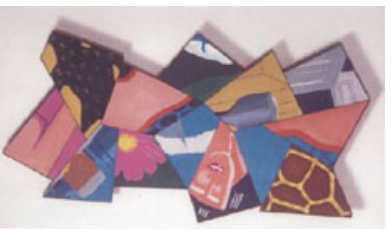

f 2004

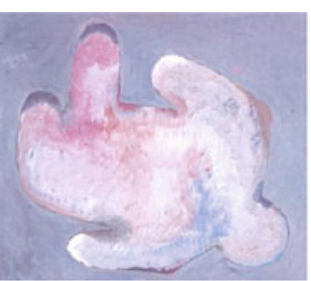

g 2004

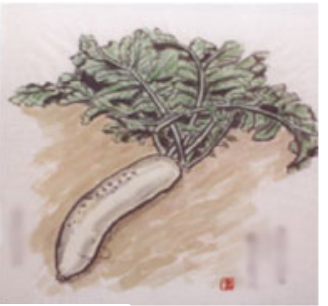

i 2005

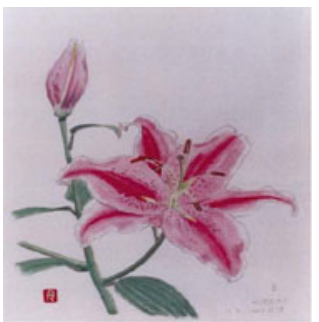

I 2007

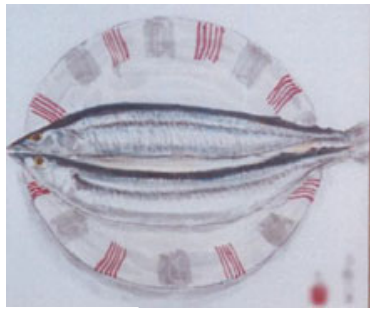

j 2006

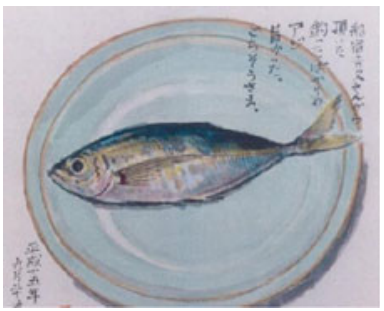

m 2008

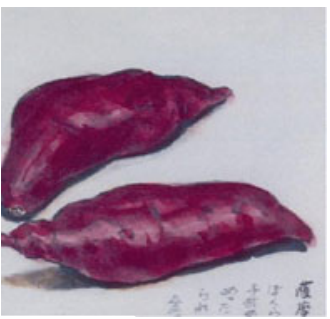

k 2007

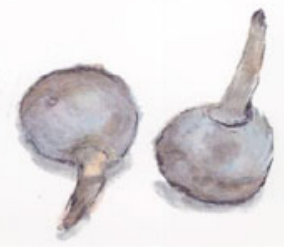

n 2009 parkinsonian symptoms gradually worsened, but he continued painting. In 2009, he started taking levodopa (600 mg/day), pramipexol (3 mg/day), and entacapone (400 mg/day). He was alert, oriented, and did not show symptoms of dementia or agnosia. He scored 30/30 in the Mini-Mental State Examination and 0 in the Hamilton Depression Rating Score. Visuospatial system assessments including a geometric drawing task, judgement of visual and horizontal, and the Benton Visual Retention Test were normal. His speech was fluent and comprehension good.
He had a mask-like face and exhibited resting tremor of the left upper and lower limbs. He showed bilateral bradykinesia, most prominent in the left upper limb, and his writing was micrographic and tremorous. He had cogwheel rigidity of both the upper limbs and could rise from a chair with some difficulty. He accomplished activities of daily living slowly with his wife's assistance. He was judged as having Hoehn and Yahr stage 3 PD. His tremor disappeared when he painted. His brain magnetic resonance imaging and electroencephalography scans were normal in 
2005 and 2009. His (99 m) Tc-ethylcysteinate dimer brain perfusion single-photon emission tomography (SPECT) results in 2006 were analyzed with a qualitative analysis program, easy $Z$ score imaging system (eZIS), and an automated quantitative analysis program, 3DSRT. eZIS demonstrated severe occipital hypoperfusion.

\section{Patient's art}

Our patient began to paint full-scale paintings at 20 years of age. He frequently exhibited his abstract paintings at Japanese art shows (Fig. 1a-f). Beginning in 2000, he gradually found it difficult to paint abstracts as it was difficult for him to deconstruct a realistic image and reconstruct it into an abstract image. Instead, he modified old drafts and exhibited them as original new works. In 2004, 1 year before the onset of PD-related movement disorders, he was unable to paint abstracts. His painting style gradually transformed into realism. Meanwhile, he felt his artistic creativity diminish to the point where he could only use half of his imagination (Fig. 1g, h) and he was not satisfied with those. He, however, continued to paint realistically (see Fig. 1i-n). He maintained the quality of realistic paintings until forced to cease painting in September 2009 due to worsening right-hand movement. Currently, he remains interested in art and indulges in photography.

\section{Discussion}

We present the first report showing changes in artistic expression-from abstract painting to realism-as an initial symptom in a PD patient, apparently caused by the lack of ability to reconstruct visual images. Premotor symptoms are involved in olfactory deficit, rapid eye movement behavior disorder, excessive daytime somnolence, depression, constipation, and erectile dysfunction [7]. Hence, this case is remarkable as it involves higher visual creativity before the onset of motor symptoms. The majority of PD patients experience diminished motor skills and gradually lose their ability to draw pictures. Chatterjee et al. [6] described a PD patient who demonstrated remarkable creativity and productivity well into the disease course. Kulisevsky described an amateur artist whose painting style, talent, and drive changed notably in association with dopaminergic treatment [8]. They argue that these cases illustrate two separate phenomena associated with longterm dopaminergic replacement in PD: (1) clinical events linked to plastic changes in frontolimbic basal ganglia circuits and (2) stimulation with long-acting drugs constraining the already narrow range of adequate dopaminergic stimulation that is necessary for optimal function of the neural systems related to the pursuit of reward. The changes in our patient's artistic ability occurred before the initiation of dopamine replacement therapy and are unlikely to have been its side effects. Certainly, dopamine replacement therapy did not cure his artistic creativity. Recently, there has been an increasing recognition of PD features unrelated to nigrostriatal dopamine deficiency. Increasing evidence suggests that the first neurons affected in PD are nondopaminergic and that SNc may become involved only after the disease is well established in other regions of the nervous system [9]. Therefore, affected nondopaminergic neurons first disturbed his ability to reconstruct and deconstruct an image, but the exact brain lesion associated with the limitation in visual creativity reported in the present study is unknown.

Skillful creation of abstract paintings requires advanced brain functions. Our patient had difficulty deconstructing and reconstructing objects into an abstract form. This dysfunction may have been overlooked had the patient not been an abstract painter. However, regardless of the mechanism, this case represents a remarkable example of the involvement of high-level visual creativity before the onset of parkinsonian symptoms such as movement, psychiatric, and autonomic nerve disorders.

\section{Conflict of interest None.}

Open Access This article is distributed under the terms of the Creative Commons Attribution Noncommercial License which permits any noncommercial use, distribution, and reproduction in any medium, provided the original author(s) and source are credited.

\section{References}

1. Miller BL, Cummings J, Mishkin F, Boone K, Prince F, Ponton M, Cotman C (1998) Emergence of artistic talent in frontotemporal dementia. Neurology 51:978-982

2. Mell JC, Howard SM, Miller BL (2003) Art and the brain: the influence of frontotemporal dementia on an accomplished artist. Neurology 60:1707-1710

3. Flaherty AW (2005) Frontotemporal and dopaminergic control of idea generation and creative drive. J Comp Neurol 493:147-153

4. Espinel CH (1996) de Kooning's late colors and forms: dementia, creativity, and the healing power of art. Lancet 347:1096-1098

5. Kleiner-Fisman G, Black SE, Lang AE (2003) Neurodegenerative disease and the evolution of art: the effects of presumed corticobasal degeneration in a professional artist. Mov Disord 18:294-302

6. Chatterjee A, Hamilton RH, Amorapanth PX (2006) Art produced by a patient with Parkinson's disease. Behav Neurol 17:105-108

7. Lim S-Y, Fox SH, Lang AE (2009) Overview of the extranigral aspects of Parkinson Disease. Arch Neurol 66(2):167-172

8. Kulisevsky J, Pagonabarraga J, Martinez-Corral M (2009) Changes in artistic style and behavior in Parkinson's disease: dopamine and creativity. J Neurol 256:816-819

9. Braak H, Del Tredici K, Rüb U, de Vos RAI, Jansen Steur ENH, Braak E (2003) Staging of brain pathology related to sporadic Parkinson's disease. Neurobiol Aging 24(2):197-211 